\title{
President's Column
}

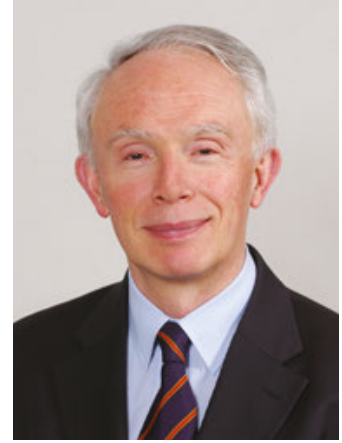

\section{All on the Same Team}

\author{
by Christopher Brett
}

$\mathrm{B}$ $y$ the time you read this column, 2019 will have ended, and with it the important celebrations of IUPAC's centenary and the International Year of the Periodic Table of the Chemical Elements (IYPT). Both of these have focused on the dissemination of knowledge, creating educational opportunities and information exchange as central ideas for IUPAC, as well as on the history of IUPAC since 1919 and the development of the periodic table. However, an ending is also a beginning; a forward-looking perspective behind the worldwide New Year 2020 celebrations at the end of one year and the beginning of the next. Remember the achievements in order not to forget, to move forward and build on them.

IUPAC's future role poses many questions of both a practical nature as well as a vision. To what extent should we try to create IUPAC's role in the future and be ready to collaborate with other international or world organizations in the implementation of society's and, in particular the chemical community's, needs? In what areas, and how, can we best contribute with our expertise and experience in chemistry?

Several years ago, IUPAC council approved a strategic plan that underpins our future development, and answers the underlying question "Why IUPAC?" The answer starts with a vision which defines our mission, the vision that IUPAC is an indispensable worldwide resource for chemistry. IUPAC's mission is that IUPAC provides objective scientific expertise and develops the essential tools for the application and communication of chemical knowledge for the benefit of humankind and the world. The words above: expertise, tools, communication, the benefit of humankind, can seem simple but can represent huge challenges.

The IUPAC mission is being accomplished and will continue in three essential ways. First, two more traditional ways which it has done throughout the past century, and for which IUPAC is recognised, and which will continue to be of critical importance. These are providing a common language for chemistry and advocating and promoting the free exchange of scientific information. They may be understood by society as technical but are crucial for the communication of science and for IUPAC to be able to contribute in ways that are understood by all, starting with the chemistry communities, both academic and industrial. The third way is fostering sustainable development, an aspect which has come to the forefront and which we can expect to grow in importance in the future as we witness the fruits of what is happening to the planet and our environment.

These are three crucial challenges, different facets of which will change over time as will their relative importance.

We recently held an interesting and informative discussion at the meeting of the IUPAC Bureau, where break-out groups were asked to say how they think that IUPAC will look in 5, in 10 or in 50 years time. It was a very illuminating exercise, not least because it gave the opportunity to look at a different status quo starting from zero, in other words how would IUPAC look if it were to be founded today as a sustainable organisation in all senses. In these middle to long term visions, the difficulties of transitioning from the current status quo to the new one could be put aside, as well as how to put this in place.

The main conclusions were:

- Given its vision and mission, IUPAC should involve the whole world. At the present, the majority of stakeholders are from countries which have some chemical industry, Can we help other countries achieve the sustainability necessary to become members of IUPAC? IUPAC as a world organisation should have members from all over the world.

\section{Contents (cont.)}

$\begin{array}{lr}\text { Conference Call } & 34 \\ \text { Spectroscopy and new horizons } & 35 \\ \text { Solution Chemistry in Action! } & 37 \\ \text { Flying Chemistry Educator Program in Ulang Bataar, Mongolia } & 41 \\ \text { Innovative Chemistry for Environmental Enhancement } & 44 \\ \text { Caribbean Celebrations } & 4\end{array}$

Where $2 b$ \& $Y$ 


\section{0-2021 IUPAC Bureau Membership}

\section{Officers}

IUPAC, of course, grapples with most of the practical challenges faced by all international organisations that deal with countries where the relative priorities for the future vary. I am sure that some of the actions we have started and future discussions will lead to a much wider geographical spread than we have at the moment.

- The organizational and administrative structure of IUPAC needs to be ready to adapt to the changing landscape in chemistry in academia and industry, but always being geared towards achieving IUPAC's strategic goals.

- The legacy of IUPAC100 and of IYPT must be fruitful. The events of 2019 have been extremely well received by the chemistry community, the scientific community and the public at large. I have seen countless examples at many events throughout the world of young people's fascination with the periodic table itself and, clearly, the chemical elements and their uses. This is also reflected in the very large number of participants in the Periodic Table Challenge, over 60000 from 133 countries, at the time of writing. It triggers their imagination, their interest in the natural world and in science, how the different elements interact with our daily lives and can be used to improve our quality of life. We must seek to ensure that these sparks become flames for the future. We need the input from the future generations to help us address current and future challenges in a responsible way, and successes should be built upon. Many celebratory events have taken place throughout the world and have been reported on. Organised by IUPAC directly, the global women's breakfast which took place on 12 February 2019 to coincide with the International Day of Women in Science was a tremendous success in bringing people together, not just women, and will be repeated in 2020 .

Chemistry has been the motor for and has been instrumental in the development of the present-day world, through new discoveries and inventions an their innovative application. We need to be aware of all the contributions of chemistry has made and will make. The future has been highlighted in the top ten new technologies-featured in Chemistry International in 2019. A further ten new technologies will be featured in 2020.

Chemistry has a very important role to play in sustainable development. Past and current efforts in this area, include green chemistry for sustainable development. Its an excellent example of an interdivisional committee whose role is to coordinate activities in

Prof. Christopher Brett, Portugal President

Prof. Javier García-Martínez, Spain Vice President

Prof. Qi-Feng Zhou, China/Beijing Past President

Prof. Richard Hartshorn, New Zealand Secretary General

Mr. Colin Humphris, United Kingdom Treasurer

Elected Members

Prof. Ghada Bassioni, Egypt

Prof. Russell J. Boyd, Canada

Prof. Mei-Hung Chiu, China/Taipei

Prof. Petr Fedotov, Russia

Prof. Mary Garson, Australia

Prof. Ehud Keinan, Israel

Prof. Christopher K. Ober, USA

Prof. Gloria Obuzor, Nigeria

Dr. Bipul Behari Saha, India

Prof. Ken Sakai, Japan

\section{Division Presidents}

Dr. Tim Wallington, USA

Physical and Biophysical Chemistry Division

Prof. Lars R. Öhrström, Sweden Inorganic Chemistry Division

Prof. Nikolay Nifantiev, Russia Organic and Biomolecular Chemistry Division

Prof. Christine Luscombe, USA Polymer Division

Dr. Zoltán Mester, Canada Analytical Chemistry Division

Prof. Hemda Garelick, United Kingdom Chemistry and the Environment Division

Prof. Rita Cornelis, Belgium Chemistry and Human Health Division

Prof. Alan Hutton, South Africa Chemical Nomenclature and Structure Representation

Other Standing Committee Chairs

Prof. Francesca Kerton, Canada CHEMRAWN Committee

Prof. Jan Apothker, Netherlands Committee on Chemistry Education

Dr. Robert Audette Committee on Chemistry and Industry

Prof. Jürgen Stohner, Switzerland Interdivisional Committee on Terminology, Nomenclature and Symbols

Dr. Leah McEwen, USA

Committee on Publications and Cheminformatics Data Standards

Prof. Pietro Tundo Interdivisional Committee on Green Chemistry for Sustainable Development

(Executive Committee members are denoted in bold). 
green chemistry and related areas such as sustainable energy in events that can be exemplified by conferences, awards, projects, and summer schools. This exemplifies IUPAC's partners and collaborators including international organisations-such as UNESCO and the organisation for the Prohibition of Chemical Weapons (OPCW)-and industry. Chemical industry concerns IUPAC in relation to chemical processes, sustainable energy, waste and the environment, health and foods, and others. IUPAC will be heavily involved in and contribute to reaching the 17 UN Sustainable Development Goals of Agenda 2030.

IUPAC is the proud recipient of one of the three Hague medals in 2019, attributed by OPCW to recognise the important collaboration between the two organisations over the last two decades in advocating the peaceful uses of chemistry and developing and promoting the Hague Ethical Guidelines. Additionally, providing information to them on scientific and technological advances and providing tools and materials for education and outreach. We seek to deepen the collaboration as we also do with other international organisations.

IUPAC will continue to work to ensure that chemical information can be distributed and understood in a digital world, with initiatives such as InChl, which has featured as one of the important achievements described in the IUPAC web stories created on the occasion of the centenary. These stories cover a wide range of IUPAC activities and point to the future. It also involves CODATA, the Committee on Data of the International Science Council (ISC). CODATA promotes global collaboration to advance Open Science and to improve the availability and usability of data for all areas of research, clearly in line with IUPAC's future objectives in this area. This is just one example of our interaction with the ISC. In the era of big data, issues include capturing data, data storage, data analysis, transfer, updating, and others.

We need to continue to emphasise dissemination through education and training, particularly where we can make a real difference. It is also an excellent illustration of how the legacy of the International Year of the Periodic Table can be envisaged, as I mentioned above. The large number of initiatives has generated enormous interest. What an advertisement for chemistry! One just needs to look at the events registered on the IYPT webpage. Most of us have been involved in the events in one way or another. It also demonstrates how a cornerstone of past and present IUPAC activities regarding chemical elements, the new elements and atomic weights can capture the public's attention. All of us are eagerly awaiting the appearance of new elements beyond 118

So, we will take steps to increase IUPAC's role and visibility, especially in countries and parts of the world where IUPAC has had less impact in the past, not forgetting where the global outreach of IUPAC both to the general scientific community and for public awareness is insufficient or too widespread. We must ensure that the outcome of the IUPAC Centenary celebrations and of IYPT strongly contribute to IUPAC's legacy and to IUPAC's future, through special activities and projects and new internal and dissemination initiatives. We must do this respecting our core values of advancing chemistry through excellence, collaboration, diversity and inclusiveness, amongst others.

We need to contribute to chemistry worldwide and to a better recognition of chemistry as an important contributor to solving the challenges that the world faces.

It is clear to me that this is what all the thousands of volunteers who have contributed and are continuing to contribute to IUPAC's work want, because we believe that we can do something worthwhile for the chemistry community. Healthy discussion and debate of ideas between the best worldwide experts leads us to the best solutions. We are all on the same team, from academia and industry, from young observers to the less young of us. We want to help the chemical industry in the quest for sustainable development not just for now but for ten, twenty and more years ahead. Can we rise to all these challenges? I believe we can and can make our future vision of IUPAC come true in a dynamic way.

Finally, as we begin a new biennium, I would like to thank you all for your dedication, in our quest to implement IUPAC's vision now and in the future.

Christopher Brett <cbrett@iupac.org> is President of IUPAC since January 2020. He is a professor of chemistry in the Faculty of Sciences and Technology, University of Coimbra, Portugal, where he has been since 1981, lecturing mainly electrochemistry, physical chemistry, materials chemistry and anaIytical chemistry. He has been an elected member of the IUPAC Bureau since 2012 and a member of the Executive Committee since 2016. He has gained extensive experience in IUPAC matters since 1994; he was President of the Physical and Biophysical Division (Division I) from 2006-2007, having been a Titular Member of the Division Committee since 2000 and Vice-President 2004-5. Before this, he was a member of the Electrochemistry Commission (Commission I.3) from 1994, having been Secretary in 1998-1999 and Chair from 2000-2001. He was President of the International Society of Electrochemistry (ISE), an associated organization of IUPAC, from 2007-2008, a member of the ISE Executive Committee from 2003-2010; and coordinator of the 2011 International Year of Chemistry activities of ISE. He was President of the Analytical Chemistry Division of the Portuguese Chemical Society (Sociedade Portuguesa de Química) in 1996-1999 and 2003-2005. 